American Journal of Applied Sciences 5 (5): 479-482, 2008

ISSN 1546-9239

(C) 2008 Science Publications

\title{
The Effect of Digital Count-Down Display on Signalized Junction Performance
}

\author{
M. R. Ibrahim, M. R. Karim and F. A. Kidwai \\ Department of Civil Engineering, Engineering Faculty, University of Malaya, \\ 50603 Kuala Lumpur, Malaysia
}

\begin{abstract}
Intersections are bottleneck in the highway networks and critical determinant of system's capacity and safety. Recently, several countdown timers had been installed at intersections in Kuala Lumpur and some other cities in Malaysia. The function of these timers is to aid drivers to judge the amount of time left for them to get the green signal for moving (starting) their vehicles as well as the amount of green time available for them to proceed across the intersection or to stop safely before the signal turns red. This advance information is supposed to help drivers in reducing their initial delay, especially for the first few vehicles and improving safety level. In the present research six intersections, three with count down timers and three with no-count down timer are analyzed to study the effect of count down timer on driver behavior, intersection approach headway and safety levels. The study suggests that countdown timer has got little effect on initial delay but the effect on headway is significant. The violation of traffic light by the drivers for countdown and normal signal is also compared.
\end{abstract}

Keywords: countdown signal, delay, capacity, intersection, urban

\section{INTRODUCTION}

Intersections in the urban highway network have a significant effect on the operation and performance of the traffic system. At the signalized intersection different directions of flow share the same road space and flow is segregated in terms of time. Due to this situation traffic flow analyses for signalized intersection is performed in a different way than uninterrupted flow. Capacity of a facility is greatly influenced by roadway, traffic and control conditions. Basic capacity for signalised intersections is defined in terms of the saturation flow rate, i.e., the capacity of the lane or approach assuming that the signal is green at all times. The saturation flow rate at signalised intersections under ideal conditions is 1900 passenger cars per hour of green per lane (pcphgpl) according to Highway Capacity Manual ${ }^{[1]}$. Prediction and knowledge of capacity are fundamental in the design, planning, operation, and layout of highway system. In the recent past, several countdown digital timers had been installed at intersections in Kuala Lumpur and some other cities in Malaysia. The function of these timers is to help drivers to judge the amount of time left for them to get the green signal for starting (moving) their vehicles. Apparently no in-depth study on its suitability in the local road and traffic environment has been done.
Research in the area of signalized intersection capacity and design has completed about half century. First US Highway Capacity Manual published in 1965 provided a detailed guideline for signalized intersection capacity analyses and design. Ibrahim et al. ${ }^{[2]}$ had carried out a study to determine the ideal saturation flow at signalised intersections under Malaysian road conditions. They adopted the method of measuring saturation flow published by the (then) Road Research Laboratory ${ }^{[3]}$. The averaged flow values were then regressed with lane widths to obtain a linear regression model as shown below:

$$
\mathrm{s}=1020+265 w, \quad \mathrm{r}^{2}=0.876
$$

where, $s$ is measured saturation flow rate in $\mathrm{pcu} / \mathrm{hr}$ and $w$ is lane width in $\mathrm{m}$. Leong et. al. ${ }^{[4]}$ has developed a new statistical approach for finding the pcu values of different vehicles at signalized intersections with respect to Malaysian traffic conditions. Kidwai and $\operatorname{Ta}^{[5]}$ have studied about the effect of various traffic, highway geometrics and control parameters on urban intersection capacity in Malaysia. Karim et. $a l .{ }^{[6]}$ presented a paper in MKJR meeting about preliminary findings on the performance of digital count down traffic signals in Malaysia. None of the previous studies has focussed exclusively on the effect of count down

Corresponding Author: Mohd Rasdan Ibrahim, Department of Civil Engineering, Engineering Faculty, University of Malaya, 50603 Kuala Lumpur, Malaysia Tel: +60-79676881, Fax: +603-79675318 
timer on traffic flow characteristics and driver behaviour. In the present research six intersections in Kuala Lumpur area have been analyzed to study the effect of count down timer on driver behavior and intersection approach headway. The study suggests that countdown timer has got little effect on initial delay but the effect on approach headway is significant. The violation of red light by the drivers for countdown and normal signal is also compared and the results are presented.

\section{METHODOLOGY}

In the present study six signalized intersections in Kuala Lumpur area are selected, three with countdown timer and three without timer. Video recording technique using digital camera is adopted to carry out field data collection. Recordings are done on weekdays during sunny weather. Data collection consists of determination of the phasing and signal timing for intersection, video recording process and intersection dimension measurement. The video camera is focused at the intersection approach to cover the stop line as well as queue length. The cassette is rum in the video cam through television to extract the data. In Malaysia nature of traffic is mix, it is difficult to find the cycles with passenger cars only. In the present study we have considered the cycles exclusively with passenger cars only in the queue, in order to get nearly ideal conditions for saturation flow. The cycles having vehicles other than passenger car are not considered. After the light turns green, time is noted down for each car when the rear axle crosses the stop line. For investigation of the effectiveness of timer in stopping the drivers after light turns red, number of cars are counted which cross the stop line (clear the intersection) after light turns to red.

\section{RESULTS AND DISCUSSION}

The traffic flow and driver behavior data for all the six intersections is analyzed and presented in this section. The parameters investigated in the present study are clearance behavior of vehicles and headway at the stop line, after light turns green and red light violation by drivers.

At the count down intersections, there is a digital display (in addition to green, red and amber lights) for the time left for a particular phase to change. For the $\mathrm{red} / \mathrm{green}$ phase there is a count down timer in red/green color to show the time left for the change of respective phase. The timer shows red color display during amber and all red time. The timer aid drivers to judge the amount of time left for them to get the green signal for moving their vehicles. To study the clearance behavior of vehicles, time is recorded when rear axle of each car crosses the stop line, after the light turns green. In the present study the cycles with at least six cars in queue are considered and the maximum number of cars in a cycle is seven as it is difficult to get the cycles exclusively with passenger cars. Figure 1 shows the variation of travel time to reach the stop line for different cars in queue. There is a wide variation of time for same car position in different cycles. This reflects the wide variation among the drivers' capabilities to maneuver at traffic light and also variation in car length. The car length in Malaysia varies from $3.2-4.8 \mathrm{~m}$, and average car length is about $4.2 \mathrm{~m}$. The discharge headway for subsequent cars in queue is computed by subtracting the time of second car to cross the stop line from the first car and so on. Figure 2 shows the variation of time headway for different cars in the queue after the light turns green. Time headways show a high variance for the same car positions in different cycles. Although the headway shows a decreasing pattern for the subsequent cars in the queue but the trend very much differs from the theoretical trend presented in US Highway Capacity Manual [1]. For some of the cycles, discharge headways even do not follow the decreasing trend for subsequent vehicles in the queue.

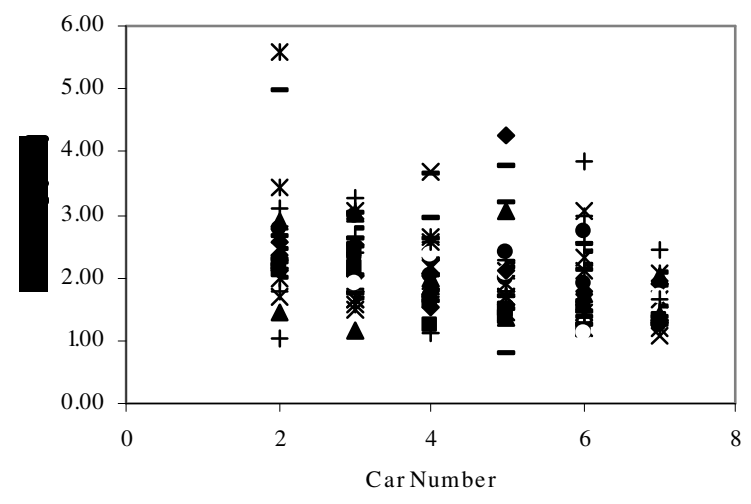

Fig. 1: Time Headway of different cars at stop line (count down timer)

The no-count down intersections are normal signalized junctions with green, amber and red display 
for each approach. For the analysis of clearance behavior of vehicles, time is recorded when rear axle crosses the stop line, after the light turns green. At all the three signalized intersections considered for study the cycles with at least six cars in queue are considered and the maximum number of cars is seven as it is difficult to get the cycles exclusively with passenger cars. Figure 3 shows the variation of travel time to reach the stop line for different cars in queue. There is a wide variation of time for same car position in different cycles. This reflects the wide variation among the drivers' capabilities and also variation in passenger car length.

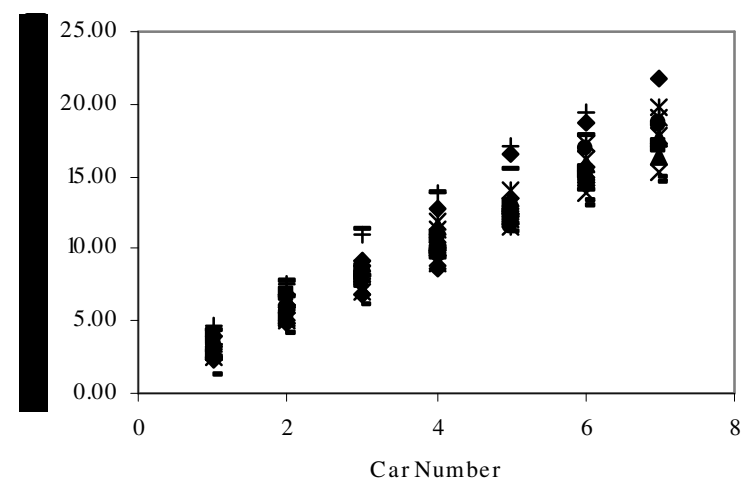

Figure 2: Time variation of different cars to reach stop line (no-count down timer)

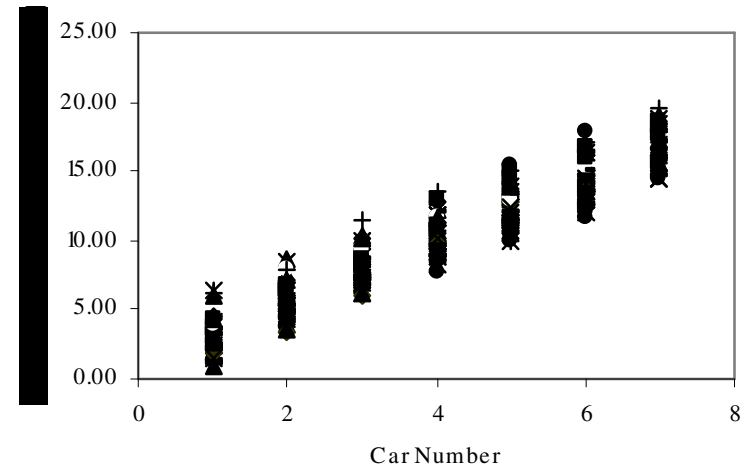

Fig 3: Time variation of different cars to reach stop line (count down timer)

For this case also discharge headway for subsequent cars in queue is computed by subtracting the time of second car to cross the stop line from the first car and so on. Figure 4 shows the variation of time headway for different cars in the queue after the light turns green. Time headways show a higher variance than the previous case for the same car positions in different cycles. Although the headway shows a decreasing pattern for the subsequent cars in the queue but the trend very much differs from the theoretical trend presented in US Highway Capacity Manual [1]. For some of the cycles, discharge headways even do not follow the theoretical trend.

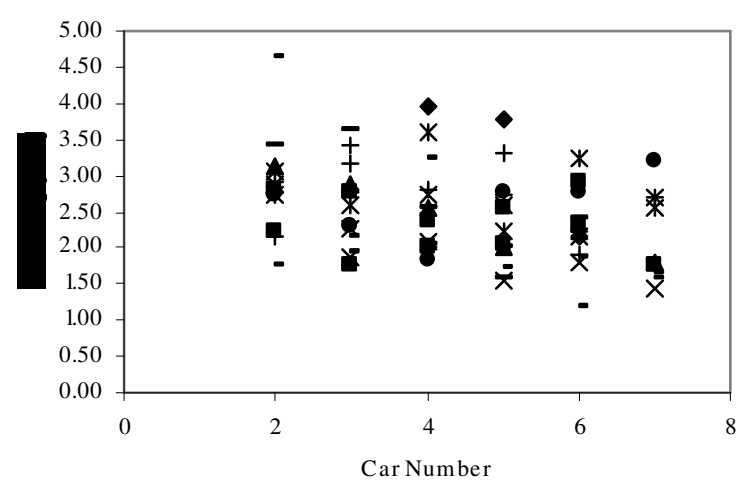

Fig. 4: Time headway of different cars at stop line (no-count down timer)

The of mean travel time to reach stop line and the headway of the average time for different cars to reach the stop line is also compared for two types of intersections. The average for travel time is taken over all the cycles for each type of intersection. In Figure 5, the values of mean travel time for the two types of intersection are very close to each other, especially for the first few vehicles.

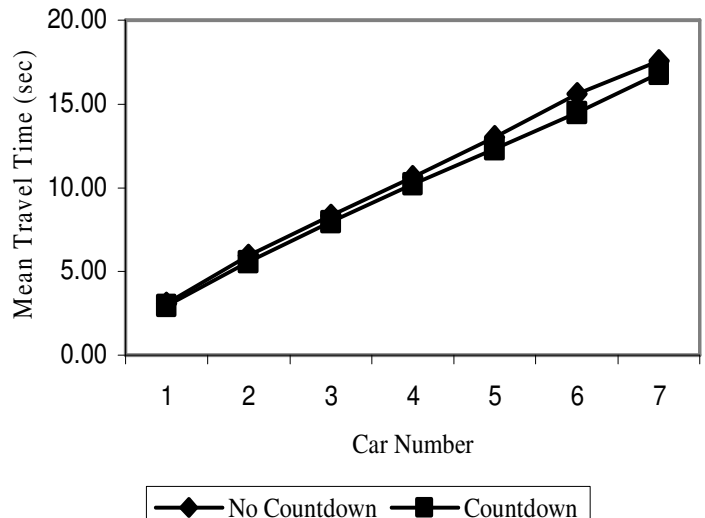

Fig. 5: Mean time of different cars to reach stop line

The mean headway shows a significant difference in Figure 6, for two types of intersections. The mean 
headway has smaller vales for all car positions for the count down intersection. This reflects that saturation flow with count down timer is significantly more than the non-count down timer.

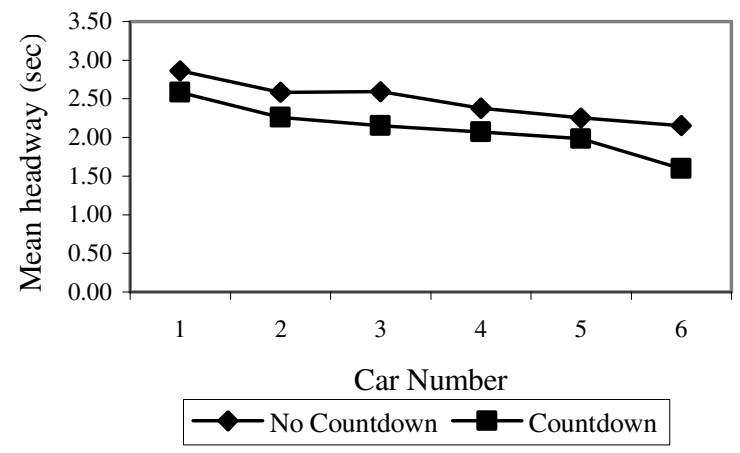

Fig. 6: Mean time headway of different cars at stop line

Finally, for the safety comparison of two types of intersections the number of cycles are recorded in which drivers violate the red light. The driver is considered to violate the red light if s/he crosses the stop line during red light. The amber time for both types of intersections is 3 seconds. For the count down case the drivers cross the stop line during red time in 24 cycles out of 88 cycles. For the non-count down case 22 out of 90 cycles are violated. Therefore the rate of violation is $30 \%$ for countdown case and $24 \%$ for noncount down case. Intuitively the violation has to be more for non-count down case.

\section{CONCLUSIONS}

Following conclusions are drawn from the present research:

- The time to reach stop line for all car positions show the similar trend for count down the nocount down situations.

- There is a wide variation for the time to reach stop line, for the same car positions the reason may be attributed to difference in drivers' abilities and car sizes.

- The discharge headway shows a high variance for the same car positions in different cycles for types of intersections. Although the headway is decreasing pattern for the subsequent cars in the queue but the trend very much differs from the theoretical trend presented in US Highway Capacity Manual, 1985.
- The digital timer has no significant effect on the travel time to stop line especially for the first few vehicles.

- The digital timer has significant effect on discharge headway for all the cars in queue.

- The rate of red light violation is more for count down intersections than for non-count down ones.

This paper is a preliminary investigation and further research should be made to validate the results obtained in this study. There is a need to prepare warrants (guidelines) for where, when and how to employ count down timers. Cost effectiveness (installation and maintenance) of digital count down timers should be studied before recommending their use.

\section{REFERENCES}

1. Highway Capacity Manual 2000. Transportation Research Board, Washington D.C

2. Ibrahim, W. H. W, Ahmad Farhan Mohd. Sadullah and Leong Lee Vien, 2002 "Determination of Ideal Saturation Flow at Signalised Intersections under Malaysian Road Conditions", MUTRF, University of Malaya, Kuala Lumpur, pp: $304-311$

3. Road Research Laboratory 1963. "A Method for Measuring Saturation Flow at Traffic Signals", Department of Scientific and Industrial Research, Road Note 34/196, HMSO, London, U.K

4. Leong Lee Vien, Wan Hashim Wan Ibrahim and Ahmad Farhan Mohd. Sadullah 2003, "Determination of passenger car equivalents using the headway ratio method at signalised intersections in Malaysia", International Journal of Engineering Science \& Technology, Volume 3, Number 2, pp; 109 - 214

5. Kidwai, F.A. and Tan, M.W. 2004, "Capacity Analysis of Signalised Urban Intersection", AWAM-2004, Universiti Sains Malaysia, Pinang, pp: 9H05-1 - 9H05-7

6. Karim, M.R, Kidwai, F.A. and Ibrahim, M.R. 2004, "A Preliminary Study on the Performance of Digital Countdown Traffic Signal", Paper presented at $3^{\text {rd }}$ MKJR meeting at Muar, Johor, Malaysia,pp: 10-11 September 2004. 